Research Article

\title{
Study on Deformation and Stability of Rock-Like Materials Retaining Structure during Collaborative Construction of Super-Adjacent Underground Project
}

\author{
Hongfu Qu, ${ }^{1}$ Lihua Wang, ${ }^{1}$ Chunlei Feng $\mathbb{D}^{2}$ Hualao Wang, ${ }^{2}$ and Xuan Zhang ${ }^{2}$ \\ ${ }^{1}$ The Fourth Engineering Co, Ltd. of CCCC First Highway Engineering Co, Ltd, Nanning 530031, China \\ ${ }^{2}$ Bridge and Tunnel Research Center, Research Institute of Highway, Ministry of Transport, Beijing 100088, China \\ Correspondence should be addressed to Chunlei Feng; fclbjtu@163.com
}

Received 9 March 2021; Accepted 31 May 2021; Published 16 June 2021

Academic Editor: Xianjie Hao

Copyright (c) 2021 Hongfu Qu et al. This is an open access article distributed under the Creative Commons Attribution License, which permits unrestricted use, distribution, and reproduction in any medium, provided the original work is properly cited.

The collaborative construction of undercrossing tunneling of Gongchang Road and the adjacent Metro Line 6 extension station section in Shenzhen is difficult and of high risk. In view of these characteristics, this paper studied the deformation and stability of rock-like material retaining structures in the process of underground engineering collaboration by combining the measured deformation data and the circular slide theory based on the limit equilibrium method. The results show that due to the difference between the supporting systems of rock-like materials on both sides and other reasons, the upper part of the retaining structure and the limited soil in the adjacent area tilt greatly to one side at the same time, and the surface settlement in the limited soil area also increases with the increase of the excavation depth of the foundation pit. On the basis of measured deformation data analysis, the mechanical model for calculating the stability concerning the relationship between the adjacent distance $L$ of the deep foundation pit and the vertical distance $D^{\prime}$ between the lowest support of the foundation pit and the bottom of retaining structures was established. Then, the calculation formula for the against basal heave stability covering different adjacent degrees was established. Besides, the applicability of the calculation method was verified by combining it with the actual engineering and related prediction theories, which further proves that the research results have certain theoretical value and engineering significance, and can provide a reference for the rock-like material retaining structures design and stability analysis of similar projects.

\section{Introduction}

With the continuous acceleration of the urbanization process in China, the number of various urban infrastructure projects also increases, which leads to the continuous improvement of building density and the increase in the construction difficulty of new projects, especially in the construction of urban threedimensional transportation [1]. In recent years, a large number of planned construction projects such as undercrossing road tunnels and subways are often constructed by the open excavation method. In order to restore normal travel and traffic order as soon as possible, the construction period is often strictly limited. Therefore, under the dual constraints of space and time, a number of collaborative construction cases of super-adjacent foundation excavation are gradually emerging, which makes the construction environment and risk factors more complicated and inconstant.

In the study of the adjacent construction of underground engineering, numerical simulation [2], on-site measurement $[3,4]$, model test $[5,6]$, and theoretical analysis [7-14] are often used. Most of the studies focus on the impact of deep foundation pit construction on the surrounding surface [15-17], existing tunnels [18], and buildings [19-21]. Combined with the analysis results of on-site measurement and numerical simulation, Sharma et al. [22] studied the influence of deep foundation pit excavation on the structural deformation of adjacent MRT tunnels. Sun et al. [23], by establishing a three-dimensional numerical model, analyzed the influence of circular foundation pit excavation on the deformation of adjacent tunnels, compared the calculation 
results with those of rectangular foundation pit excavation under the same excavation amount, and analyzed the deformation differences caused by the two excavation forms. Schuster et al. [24] studied the damage potential assessment of buildings adjacent to the new foundation pit during excavation. The new assessment methods include a variety of models, which are used to assess the horizontal deformation, angular deformation, and lateral strain of buildings, as well as the potential damage degree of buildings near the excavation. Taking the foundation excavation of three transfer stations with strong proximity in Chengdu Jincheng Square as an example, Wang et al. [25] combined the plate shell theory, numerical simulation, and on-site measurement and deeply studied the deformation of rock-like material retaining structures and mechanical problems caused by excavation and unloading of foundation pit, so as to obtain the influence characteristics of unilateral excavation of large foundation pits in comprehensive transfer station groups on the deformation response of existing stations.

To sum up, previous studies on concurrent construction of super-adjacent deep foundation excavation are very few. Instead, most of them focus on the influence of new construction on existing projects, which is the force transfer mechanism among new foundation pitsoil-existing projects. The undercrossing tunnel project of Gongchang Road in Shenzhen on which this paper relied is constructed in parallel with the super-adjacent extension of Metro Line 6 for a long distance. Its force transfer mechanism is among new foundation pit-soilnew foundation pit or tunnel, and the two projects used different forms of rock-like material retaining structures Since it involves the construction safety risk of two or more projects, the research on the deformation characteristics and stability of this kind of foundation pit construction is of great significance. Therefore, this paper studies the deformation characteristics and stability of the rock-like material retaining structures between superadjacent road tunnels by open excavation and subway stations through the analysis of measured deformation data and the optimization of common deep foundation pit stability analysis theory, which can provide a reference for the retaining system design of similar projects.

\section{Project Overview}

2.1. Project Introduction. Shenzhen is a coastal city in the south of Guangdong Province and a special economic zone in China. The coverage of the undercrossing tunnel project of Gongchang Road in Shenzhen starts from the west side of Guangqiao Road intersection (design starting point K0+000) and ends at Dongguan boundary (design ending point $K 3+559.691)$. The traffic location of the site is shown in Figure 1. The total length of the design line is $3559.671 \mathrm{~m}$, and the design width is about $40-70 \mathrm{~m}$. It is a primary trunk road, among which $K 0+440 \sim K 3+145$ is an underground (tunnel) section with a design width of about $29.0 \mathrm{~m}$, while $K 0+000 \sim K 0+440$ and $K 3+145 \sim K 3+559.691$ are surface sections.

The underground (tunnel) section is planned to be constructed by the open excavation method. The buried depth of the tunnel floor is about $3 \sim 20 \mathrm{~m}$ below the existing ground. The importance level of foundation pit retaining structure is grade I, grade II, and grade III, respectively. The south side of the proposed site is close to the extension project of Metro Line 6, and the metro extension is set parallel to the main channel of the project. The main underground channel is close to Sun Yat-Sen University Station, shield tunnel section, and Science and Technology City Station from west to East. The $K 0+600 \sim K 1+074$ and $K 2+716 \sim K 2+900$ sections are close to Sun Yat-Sen University Station and Science and Technology Town Station of Metro Line 6 extension, respectively, and their horizontal distance to the two stations is between 2.89 and $5.25 \mathrm{~m}$, which belongs to the ultra-adjacent construction project.

\subsection{Geological and Hydrological Conditions of the Project.} According to the on-site investigation and indoor geotechnical test results, the strata distributed along the site mainly include artificial fill layer $(\mathrm{Qml})$, quaternary Holocene alluvial and diluvial layer $(\mathrm{q} 4 \mathrm{al}+\mathrm{pl})$, quaternary Holocene swamp sedimentary layer $(\mathrm{q} 4 \mathrm{~h})$, quaternary Holocene sloping and diluvial layer $(\mathrm{q} 4 \mathrm{dl}+\mathrm{pl})$, quaternary upper Pleistocene alluvial and diluvial layer $(\mathrm{q} 3 \mathrm{al}+\mathrm{pl})$, and quaternary eluvial layer (Qel). The bedrock underlying the site includes Jurassic sandy mudstone $(J)$ and Caledonian mixed granite $(\mathrm{O} 1 \mathrm{~N})$. The stratigraphic distribution diagram is shown in Figure 2, and the physical and mechanical parameters of the strata are shown in Table 1.

The main aquifers of the site can be divided into three types: the first type is artificial fill layer with poor water permeability and bearing, which can form upper stagnant water locally. The second type is the quaternary sand layer with strong water bearing and permeability, the groundwater in which is pore phreatic water. The third type is strongly and moderately weathered bedrock zone, whose water content and water permeability are mainly controlled by the development degree of stratum fissures, and the groundwater in it is bedrock fissure water, which is also slightly pressured. Other strata are layers with weak water bearing and permeability or relative aquicludes.

2.3. Retaining System and Excavation Method. The $K 0+600 \sim K 1+074$ section of the Gongchang Road Project and Sun Yat-Sen University Station adopts the method of subsection and layering for stepped slope excavation. The longitudinal section diagram of the excavation method is shown in Figure 3, in which the change of excavation depth only represents that of the Gongchang Road Project, and that of Sun Yat-Sen University Station is basically maintained at about $20.3 \mathrm{~m}$.

The schematic diagram of the retaining structure and internal support form of the foundation pits on both sides is shown in Figure 4, and the specific parameters are shown in Table 2. The usage of rock-like materials is shown in Table 3. The foundation pit retaining system of the Gongchang Road Project adopts the form of support pile and internal support, and the retaining structure is composed of a row of secant 


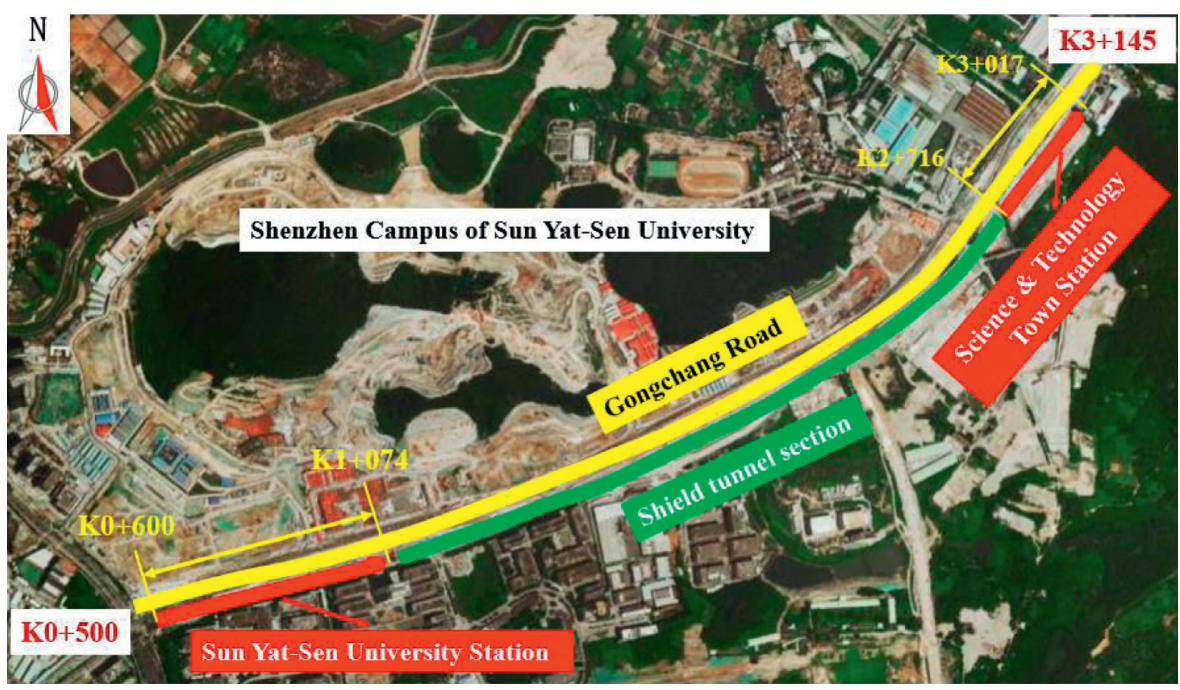

FIGURE 1: Relative position relationship and surrounding environment between the undercrossing tunnel project of the Gongchang Road and Metro Line 6 extension.

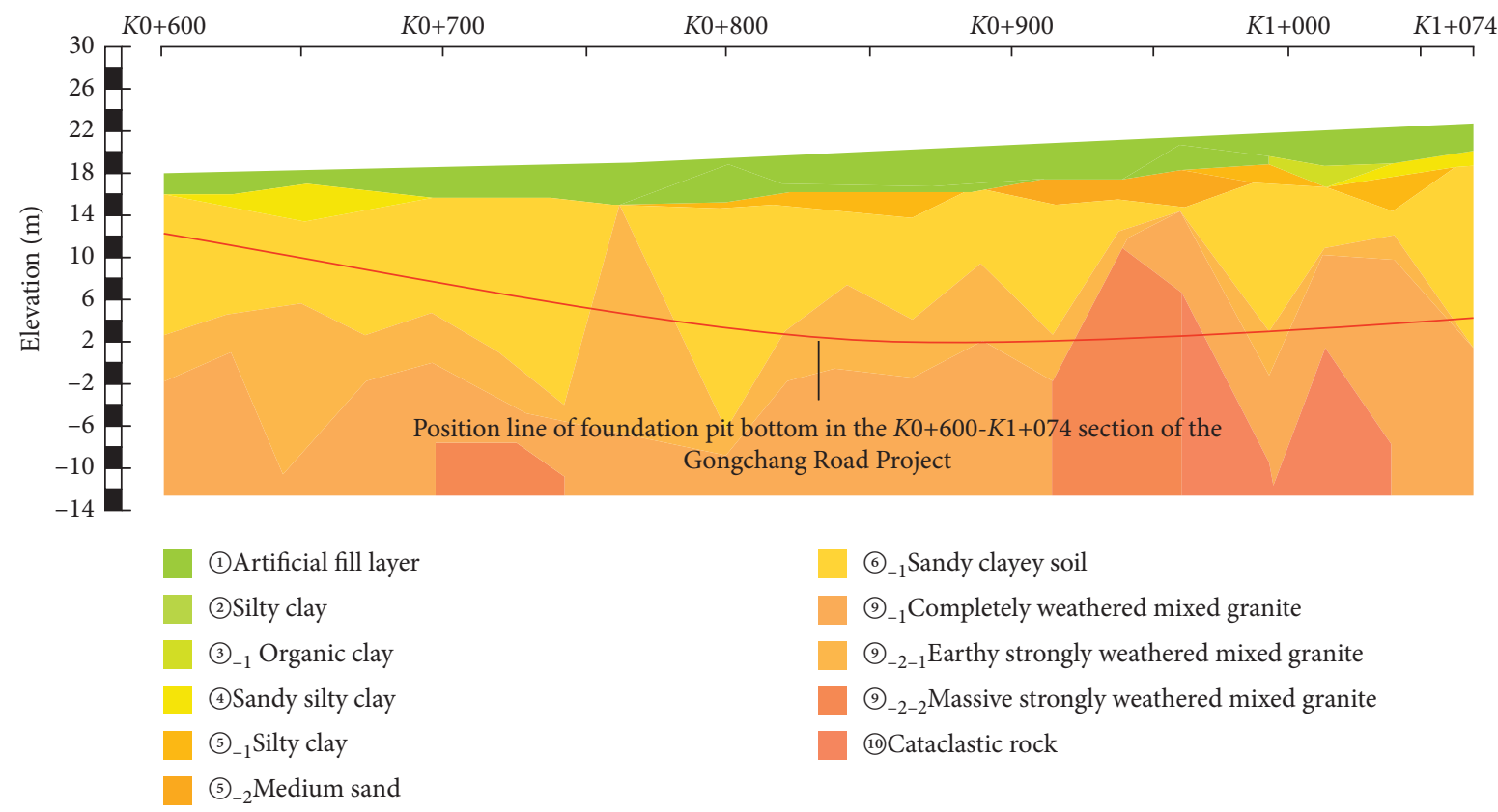

FIGURE 2: Longitudinal geological profile of $K 0+600 \sim K 1+074$ section of the Gongchang Road Project.

Ф1200@1400 mm drilled grouting piles and $\Phi 800$ mm highpressure jet grouting piles. The arrangement is shown in the left schematic diagram of Figure 4(a). At the same time, a row of \$800@600 double-pipe high-pressure jet grouting piles is used outside the retaining structure as the waterproof curtain; there are three internal supports, and the first one is $800 \mathrm{~mm} \times 800 \mathrm{~mm}$ eight-claw reinforced concrete support, with a horizontal spacing of $9 \mathrm{~m}$. The second and third supports are made of $\Phi 806(t=16)$ steel pipe, with a horizontal spacing of $3 \mathrm{~m}$. The foundation pit retaining system of Sun Yat-Sen University Station adopts the form of a diaphragm wall and internal support. The thickness of the diaphragm wall is $800 \mathrm{~mm}$, as shown in the right schematic diagram of Figure 4(a). There are three internal supports.
The first internal support is $700 \mathrm{~mm} \times 1000 \mathrm{~mm}$ reinforced concrete support, with a horizontal spacing of $9 \mathrm{~m}$. The second to third internal supports are $\Phi 609(t=16)$ steel pipe support, with a horizontal spacing of $3 \mathrm{~m}$.

2.4. Construction Risk Analysis. It can be seen from the above project overview that both the undercrossing tunnel project of Gongchang Road and the adjacent subway station are constructed by open excavation method, with a large construction scale; and the project site is located in the urban construction intensive area, with tight construction period, complex surrounding environment, and narrow construction space. Due to the parallel layout, collaborative construction, and cross- 
TABLE 1: Main physical and mechanical parameters of strata.

\begin{tabular}{|c|c|c|c|c|c|c|c|}
\hline \multirow[t]{2}{*}{ Strata } & \multirow[t]{2}{*}{$\gamma\left(\mathrm{kN} / \mathrm{m}^{3}\right)$} & \multirow[t]{2}{*}{$\gamma_{\mathrm{sat}}\left(\mathrm{kN} / \mathrm{m}^{3}\right)$} & \multirow[t]{2}{*}{$E_{s}(\mathrm{MPa})$} & \multirow[t]{2}{*}{$E_{o}(\mathrm{MPa})$} & \multicolumn{2}{|c|}{$\begin{array}{l}\text { Natural } \\
\text { condition }\end{array}$} & \multirow[t]{2}{*}{$K(\mathrm{~m} / \mathrm{d})$} \\
\hline & & & & & $\Phi\left(^{\circ}\right)$ & $C(\mathrm{kPa})$ & \\
\hline Artificial fill layer (Qml) 1 & 18.3 & 18.6 & 5.0 & 8.0 & 18 & 15 & $0.5 / 0.2$ \\
\hline Silty clay $(\mathrm{Q} 4 \mathrm{al}+\mathrm{pl}) 2$ & 18.5 & 19.0 & 5.0 & 13 & 16 & 23 & 0.01 \\
\hline Organic clay $(\mathrm{Q} 4 \mathrm{~h}) 3_{-1}$ & 17.5 & 17.9 & 3.0 & 4.0 & 4 & 15 & 0.01 \\
\hline Sandy silty clay $(\mathrm{Q} 4 \mathrm{dl}+\mathrm{pl}) 4$ & 18.5 & 18.8 & 7 & 22 & 18 & 24 & 0.01 \\
\hline Silty clay $(\mathrm{Q} 3 \mathrm{al}+\mathrm{pl}) 5_{-1}$ & 18.3 & 18.6 & 6 & 13 & 16 & 18 & 0.01 \\
\hline Medium sand $(\mathrm{Q} 3 \mathrm{al}+\mathrm{pl}) 5_{-2}$ & 19.5 & 20.0 & - & 30 & 32 & - & 10 \\
\hline Sandy clayey soil (Qel) $6-1$ & 18.5 & 18.9 & 8 & 22 & 23 & 23 & 0.05 \\
\hline Completely weathered mixed granite (O1N) $9_{-1}$ & 19.0 & 19.3 & 12 & 60 & 28 & 22 & 0.1 \\
\hline Earthy strongly weathered mixed granite $(\mathrm{O} 1 \mathrm{~N}) 9_{-2-1}$ & 20.0 & 20.4 & 16 & 170 & 33 & 45 & 0.5 \\
\hline Massive strongly weathered mixed granite $(\mathrm{O} 1 \mathrm{~N}) 9_{-2-2}$ & 21.5 & 21.8 & - & 250 & 34 & 50 & 1.0 \\
\hline Cataclastic rock $(\mathrm{F})$ & 21.0 & 21.5 & 18 & 180 & 34 & 45 & 1.0 \\
\hline
\end{tabular}

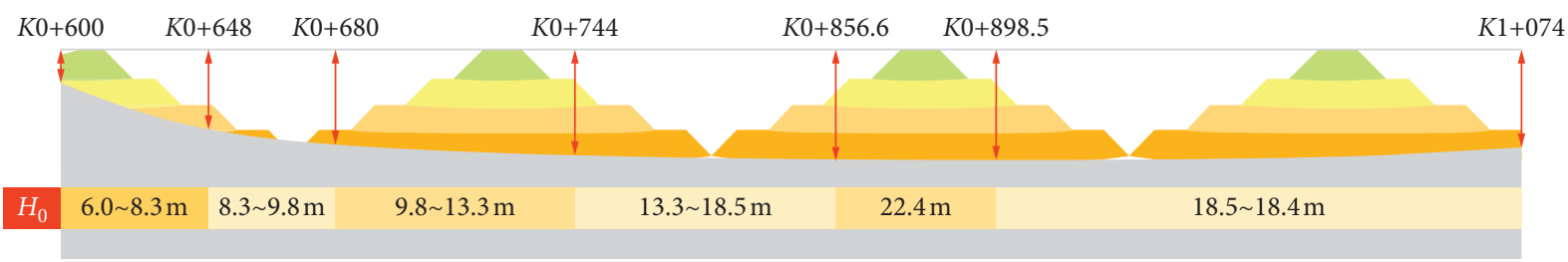

FIgURE 3: Longitudinal section diagram of foundation pit excavation method in $K 0+600-\mathrm{K} 1+074$ section of the Gongchang Road Project.

interference between the project and adjacent metro lines, the deformation and stability of the project during construction are faced with high safety risks. Therefore, this paper takes the $K 0+600 \sim K 1+074$ section of the Gongchang Road Project and Sun Yat-Sen University Station as the main research object and focuses on the rock-like material retaining structure stability of super-adjacent area on the basis of sorting and analyzing the measured deformation data.

\section{Analysis of Measured On-Site Deformation Data}

3.1. Layout of On-Site Deformation Monitoring. The automatic monitoring system of the project is composed of parts including monitoring equipment, data acquisition and analysis, signal transmission, and receiving terminals. Among them, the deep horizontal displacement $\delta_{h}$ of the retaining structure and the surrounding ground subsidence $\delta_{v}$ in the monitoring project are the two main indexes in the study of deformation characteristics of the deep foundation pit. The general layout of two kinds of deformation monitoring of foundation pits on both sides in this paper is shown in Figure 5(a). The horizontal distance between monitoring points $\delta_{h}$ and $\delta_{v}$ in the Gongchang Road Project is about $50 \mathrm{~m}$ and $40 \mathrm{~m}$, respectively, and that in Sun Yat-Sen University Station is $15 \sim 18 \mathrm{~m}$. The layout of monitoring points in each monitoring section of ground subsidence of foundation pits on both sides is shown in Figure 5(b).

\subsection{Deep Horizontal Displacement of Retaining Structures.} In order to facilitate the analysis and explanation of the follow-up study, the retaining structures of foundation pits on both sides are named according to the relative orientation. The retaining structures on the north and south sides of the Gongchang Road site and the north and south sides of Sun Yat-Sen University Station are named as NN, $N S, S N$, and SS respectively, as shown in Figure 5(b).

Figures 6(a) and 6(b), respectively, show the deformation of the retaining structures after the deep foundation pits in the $K 0+600 \sim K 1+074$ section of the Gongchang Road undercrossing tunnel and of Sun Yat-Sen University Station is excavated to the bottom. The specific deformation characteristic values are shown in Table 4 , in which $\delta_{h \text {-max }}, \delta_{h \text {-min }}$, and $\delta_{h \text {-avg }}$ are the maximum, minimum, and average values of the deformation of the retaining structures toward the pit. This section starts from the overall deformation trend of the retaining structures of foundation pits on both sides and first analyzes the $N N$ and $S S$ retaining structure with semiinfinite soil on one side and then analyzes the NS and $S N$ retaining structure with finite soil on one side. The deformation can be summarized as follows:

(1) The overall deformation of the $N N$ and SS retaining structure is toward the pit, and its deformation form is consistent with that of the typical retaining structure [26]. Among the 11 monitoring sections of the $N N$ retaining structure, the top of 8 sections are horizontally deformed toward the pit, with an average displacement of $9.85 \mathrm{~mm}$; among the 8 monitoring sections of SS retaining structure, the top of 5 sections are horizontally deformed toward the pit, with an average displacement of $3.12 \mathrm{~mm}$. In the deep horizontal displacement of retaining structures, the maximum horizontal displacement depth of $N N$ retaining structure is about $9 \sim 15 \mathrm{~m}$, while the maximum displacement $\delta_{h-\max }$ is $36.96 \mathrm{~mm}$, and 


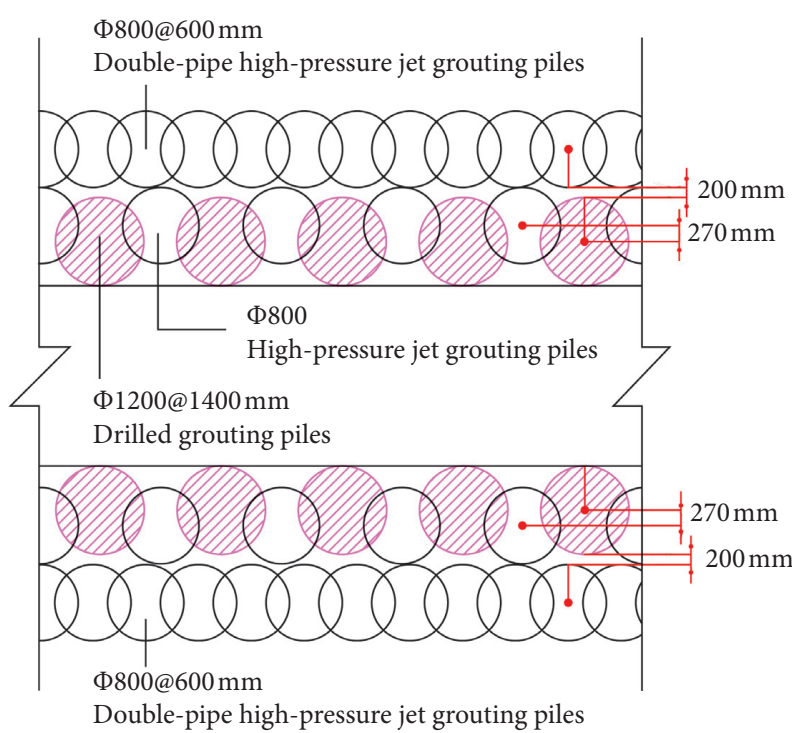

$K 0+600-K 1+074$ section of Gongchang Road Project

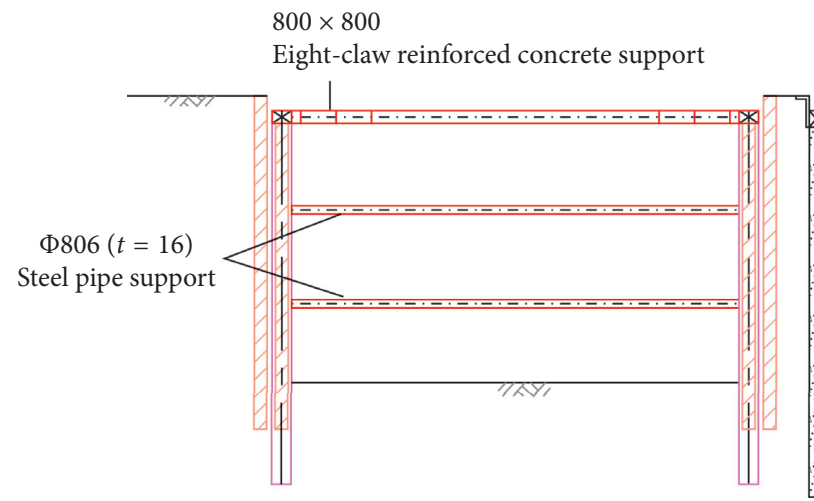

$K 0+600-K 1+074$ section of Gongchang Road Project

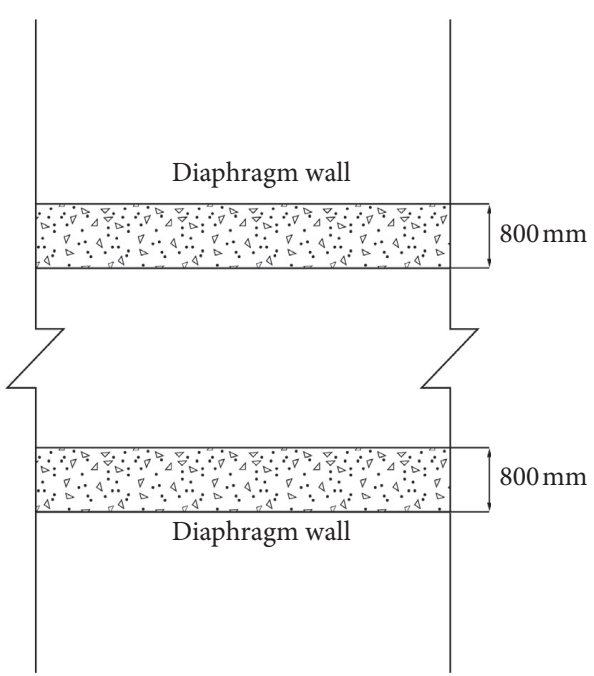

Sun Yat-Sen University Station

$700 \times 1000$

Reinforced concrete support

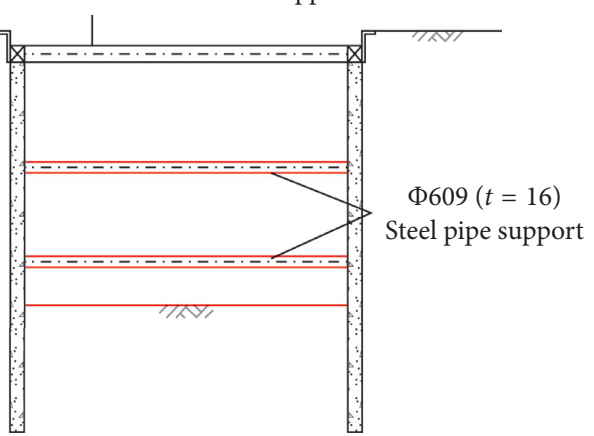

Sun Yat-Sen University Station

(b)

FIGURE 4: Schematic diagram of foundation pit retaining system on both sides: (a) retaining structure; (b) internal support.

TABLE 2: Basic parameters of foundation pit retaining system on both sides.

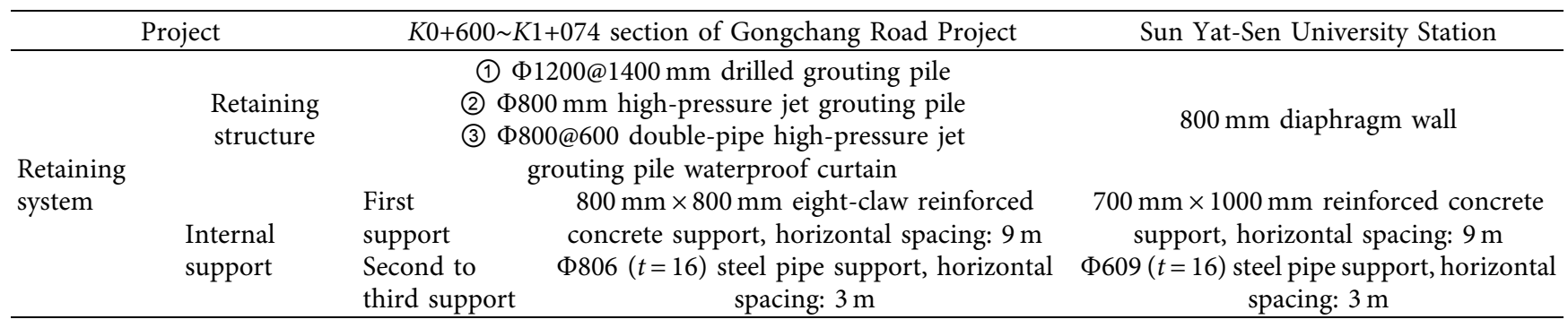

TABLE 3: Material parameters of rock-like material retaining structure.

\begin{tabular}{lccc}
\hline Project & Material of retaining structure & Material of the first inner support \\
\hline $\begin{array}{l}\text { K0+600-K1+074 section of Gongchang } \\
\text { Road Project }\end{array}$ & $\begin{array}{c}\text { Drilled grouting pile } \\
\text { Pressure jet grouting } \\
\text { pile }\end{array}$ & $\begin{array}{c}\text { Underwater concrete (C30) } \\
\text { Ordinary portland cement (level } \\
\text { Pun Yat-Sen University Station }\end{array}$ & $\begin{array}{c}\text { Shrinkage compensating concrete } \\
\text { (C30) }\end{array}$ \\
\hline Diaphragm wall & Underwater concrete (C35) & Concrete (C30) \\
\hline
\end{tabular}




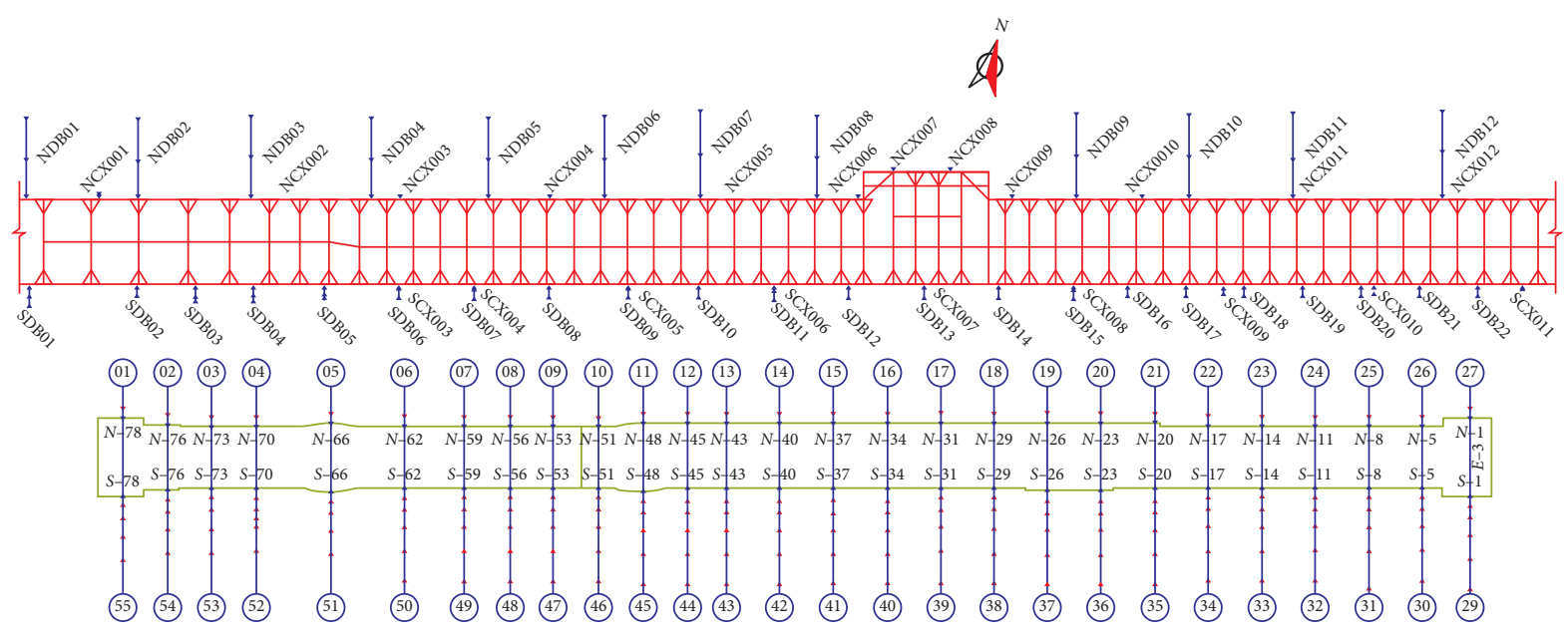

(a)

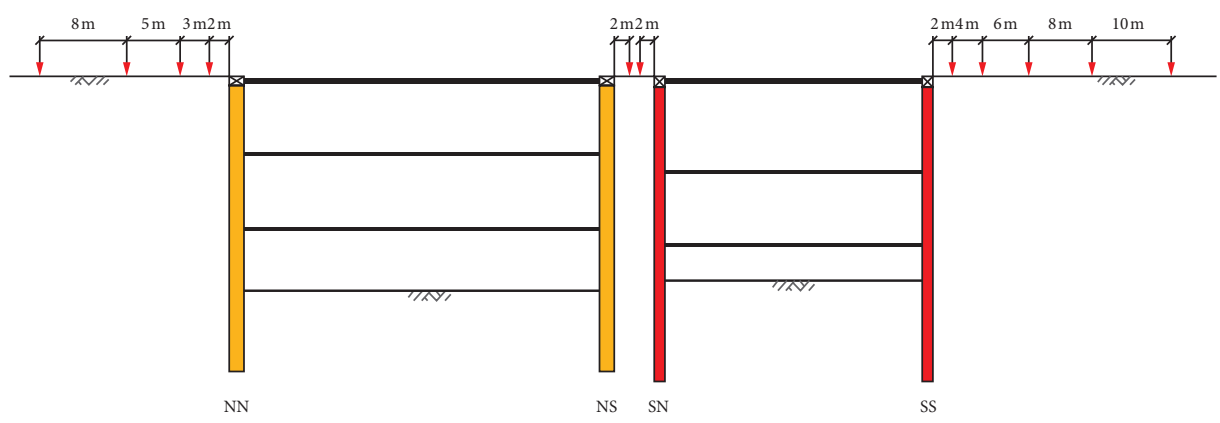

(b)

FIGURE 5: Distribution of project monitoring sections and points of foundation pits on both sides: (a) general monitoring layout; (b) monitoring points of ground subsidence of foundation pits on both sides and naming of retaining structures.

the average maximum displacement is $18.8 \mathrm{~mm}$. The maximum horizontal displacement depth of $S S$ retaining structure is about $11 \sim 14 \mathrm{~m}$, and the maximum displacement is $30.26 \mathrm{~mm}$, while the average maximum displacement is $23.49 \mathrm{~mm}$

(2) The deformation trend of $N S$ and $S N$ retaining structure is relatively complex: among the 16 monitoring sections of NS and $S N$ retaining structure, the top of 14 sections are horizontally displaced to the north, which drives the retaining structure with an embedded depth of about $10 \mathrm{~m}$ to incline to the north to different degrees. The horizontal displacement of the top of NS retaining structure ranges from $0.73 \mathrm{~mm}$ to $25.48 \mathrm{~mm}$, with an average horizontal displacement $\delta_{t \text {-NS }}$ of $10.82 \mathrm{~mm}$; the horizontal displacement of the top of $S N$ retaining structure ranges from $0.49 \mathrm{~mm}$ to $22.43 \mathrm{~mm}$, with an average horizontal displacement $\delta_{\mathrm{t}-\mathrm{SN}}$ of $14.06 \mathrm{~mm}$. In the deep horizontal displacement of the retaining structure, the maximum horizontal displacement depth of the NS retaining structure is about $1 \sim 7 \mathrm{~m}$, and the maximum displacement $\delta_{h \text {-max }}$ is $25.48 \mathrm{~mm}$, while the average maximum displacement is $12.81 \mathrm{~mm}$. The maximum horizontal displacement depth of $S N$ retaining structure is about $11 \sim 16 \mathrm{~m}$, and the maximum displacement is $24.94 \mathrm{~mm}$, while the average maximum displacement is $21.73 \mathrm{~mm}$

3.3. Ground Subsidence and Deformation outside the Pit. In the existing research on ground subsidence, most of the research objects are semi-infinite soil. The research results concerning measured deformation of ground subsidence include ground subsidence mode, main influence range, maximum subsidence value, and its location. In this paper, both the north side soil of the foundation pit in the $K 0+600 \sim K 1+074$ section of Gongchang Road Project and the south side soil of the foundation pit in Sun Yat-Sen University Station are semi-infinite, so the measured deformation can be analyzed from the above aspects, as shown in Figure 7.

As the adjacent area is relatively narrow, the horizontal distance between adjacent retaining structures is about $3.29 \mathrm{~m}$ in the $K 0+600 \sim K 0+648$ section and about $5.25 \mathrm{~m}$ in the $K 0+648 \sim K 1+074$ section, so the soil between super-adjacent foundation pits is finite soil. A row of subsidence monitoring points is arranged 


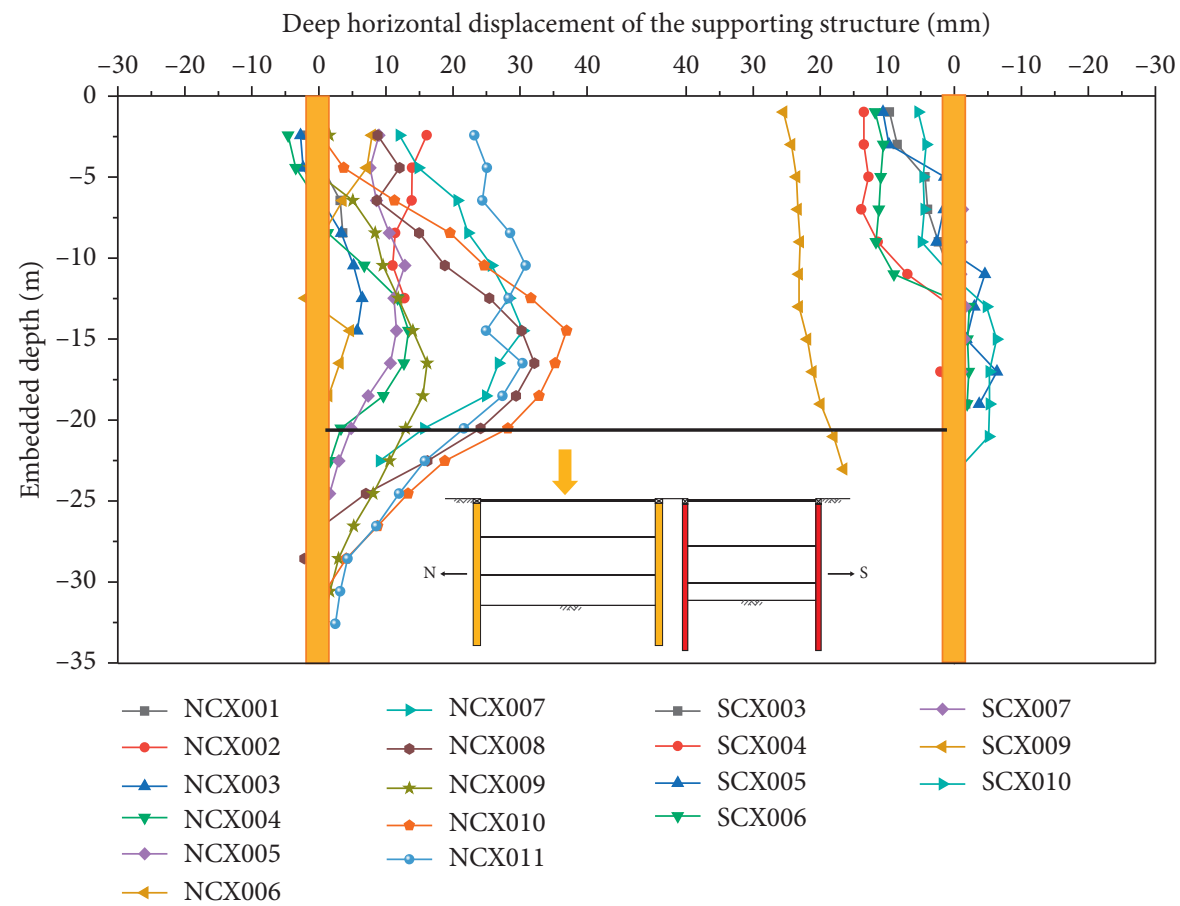

(a)

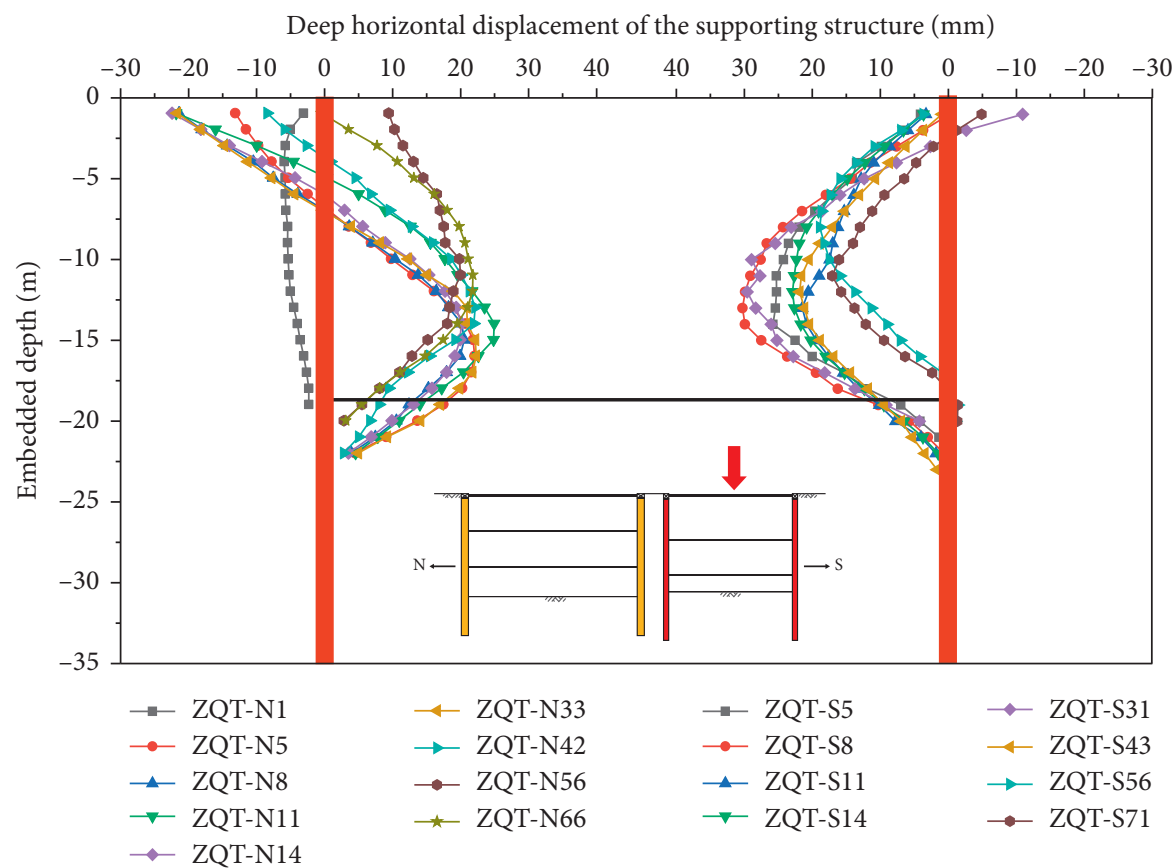

(b)

FiguRE 6: Deep horizontal displacement of the retaining structures: (a) K0+600 K1+074 section of Gongchang Road Project; (b) Sun YatSen University Station.

longitudinally on the ground surface of the area with a distance of $2 \mathrm{~m}$ away from the adjacent retaining structure of the foundation pits on both sides of the site. In this paper, the surface deformation law of collaborative construction of super-adjacent foundation pit is divided into two parts: ground subsidence of semi-infinite soil outside the pit and ground subsidence of finite soil.
3.3.1. Ground Subsidence in Semi-Infinite Soil Region. The data statistics of ground subsidence monitoring sections on the north side of the foundation pit in the $K 0+600 \sim K 1+074$ section of Gongchang Road Project and the south side of the foundation pit of Sun Yat-Sen University Station are shown in Figures $7(\mathrm{a})$ and $7(\mathrm{~b})$, respectively, in which the red solid line is the subsidence curve 
TAвLE 4: Comparison of characteristic values of deep horizontal displacement of retaining structures of foundation pits on both sides.

\begin{tabular}{|c|c|c|c|c|c|c|}
\hline \multirow[t]{2}{*}{ Project } & \multicolumn{3}{|c|}{$\begin{array}{l}\text { Characteristic values of deep } \\
\text { horizontal displacement of the } \\
\text { retaining structure on the north } \\
\text { side }(\mathrm{mm})\end{array}$} & \multicolumn{3}{|c|}{$\begin{array}{l}\text { Characteristic values of deep } \\
\text { horizontal displacement of the } \\
\text { retaining structure on the south } \\
\text { side }(\mathrm{mm})\end{array}$} \\
\hline & $\delta_{h-\max }$ & $\delta_{h-\min }$ & $\delta_{h \text {-avg }}$ & $\delta_{h-\max }$ & $\delta_{h \text {-min }}$ & $\delta_{h \text {-avg }}$ \\
\hline$K 0+600 \sim K 1+074$ section of Gongchang Road Project & 36.96 & 3.56 & 18.8 & 25.48 & 5.38 & 10.92 \\
\hline Sun Yat-Sen University Station & 24.94 & 19.99 & 19.06 & 30.26 & 17.08 & 23.49 \\
\hline
\end{tabular}

fitted according to the measured data points of the two foundation pits, while the blue dotted line is the subsidence model $f\left(d / H_{e}, \delta_{v} / \delta_{v-\max }\right)$ calculated according to the subsidence form prediction theory of Hsieh and $\mathrm{Ou}$ [27]. It can be seen from the figure that the main influence range $\left(d / H_{e}\right)=2, \quad\left(\delta_{v} / \delta_{v-\max }\right)=0.1$ and the location where the maximum subsidence occurs $\left(d / H_{e}\right)=0.5,\left(\delta_{v} / \delta_{v-\max }\right)=1$ in the predicted ground subsidence model are in good agreement with the measured ones. The specific measured statistics are shown in Table 5.

Because the maximum excavation depth $H_{\mathrm{e}}$ of the two foundation pits is close in value, the influence range of ground subsidence and the location of the maximum subsidence after excavation are also close, which are in the range of 10 12 $\mathrm{m}$ and $36 \sim 41 \mathrm{~m}$, respectively. However, the fact that the excavation width of the two foundation pits is different and the stiffness $E I / \gamma_{\mathrm{w}} h_{\text {avg }}^{4}$ of the retaining system of the diaphragm wall is higher than that of the pile wall structure [26] may be one of the main reasons for the fact that the overall ground subsidence of the foundation pit in $K 0+600 \sim K 1+074$ section of Gongchang Road Project is larger than that of the foundation pit of Sun Yat-Sen University Station.

3.3.2. Ground Subsidence in Finite Soil Area. Figure 8 shows the measured ground subsidence values in the section which is $2 \mathrm{~m}$ away from the south side of the foundation pit in the $K 0+600 \sim K 1+074$ section of the Gongchang Road Project and the section which is $2 \mathrm{~m}$ away from the north side of the foundation pit of Sun Yat-Sen University Station. After connection, the longitudinal deformation curve is formed. The starting point of abscissa in the figure corresponds to the location of $K 0+600$ of the Gongchang Road Project. The specific measured statistics are shown in Table 6.

It can be seen from the figure that with the increase of abscissa, the two longitudinal deformation curves of ground subsidence in finite soil area show a gradually increasing trend, and the abscissa of the increasing inflection point is $250 \sim 300 \mathrm{~m}$. The maximum values of the two curves are $-18.24 \mathrm{~mm}$ and $-23.2 \mathrm{~mm}$, respectively, and the average values are $-11.77 \mathrm{~mm}$ and $-14.34 \mathrm{~mm}$, respectively. The range of these inflection points is included in the $K 0+856.6 \sim K 0+898.5$ section. According to the actual working conditions, the excavation depth of the foundation pit of Sun Yat-Sen University Station basically remains unchanged, while the excavation depth of the foundation pit in the K0+600 K1+074 section of Gongchang Road Project gradually increases with the mileage, which reaches the maximum in $K 0+856.6 \sim K 0+898.5$ section (corresponding to the range of $250 \sim 300 \mathrm{~m}$ on the abscissa in Figure 8), and then decreases slightly. This trend is consistent with the change of longitudinal curve of the ground subsidence in finite soil area.

3.4. Summary of the Deformation. Through the above statistical analysis of the measured deformation data, it can be found that for different forms of rock-like material retaining structure, the lateral displacement law of the retaining structure with semi-infinite soil on one side of the superadjacent deep foundation pit and the deformation law of ground subsidence on that side are basically consistent with the existing research conclusions of the deformation of a single foundation pit; the top of the retaining structure with finite soil on one side and a certain range below has a tendency of deformation to the north side at the same time, and the top displacement value is larger. At the same time, due to the narrow range of finite soil area, the ground subsidence deformation analysis is mainly based on the longitudinal deformation trend, which shows that the subsidence value increases with excavation depth.

In the collaborative construction process of super-adjacent deep foundation pits, the deformation form and degree of the adjacent area soil and retaining structures may directly affect the stability of foundation pits on both sides. Once the adjacent retaining structure has a large displacement to the same side, it is likely that the foundation pits on both sides will lose stability to different degrees at the same time, so special attention should be paid to the stability of finite soil and the rock-like material retaining structures on both sides. The against basal heave stability of deep foundation excavation is particularly important, which is related not only to the stability and safety of foundation pits but also to the deformation of foundation pits. Therefore, based on the measured deformation data analysis and the existing theoretical mechanical model of the against basal heave stability, the stability analysis method for super-adjacent soil and rock-like material retaining structure characteristics is further studied.

\section{Analysis on the Against Basal Heave Stability in Collaborative Construction of Ultra-Adjacent Deep Foundation Pits}

The common analysis method of the against basal heave stability of single foundation pit adopts the calculation theory of circular sliding mode based on limit equilibrium 


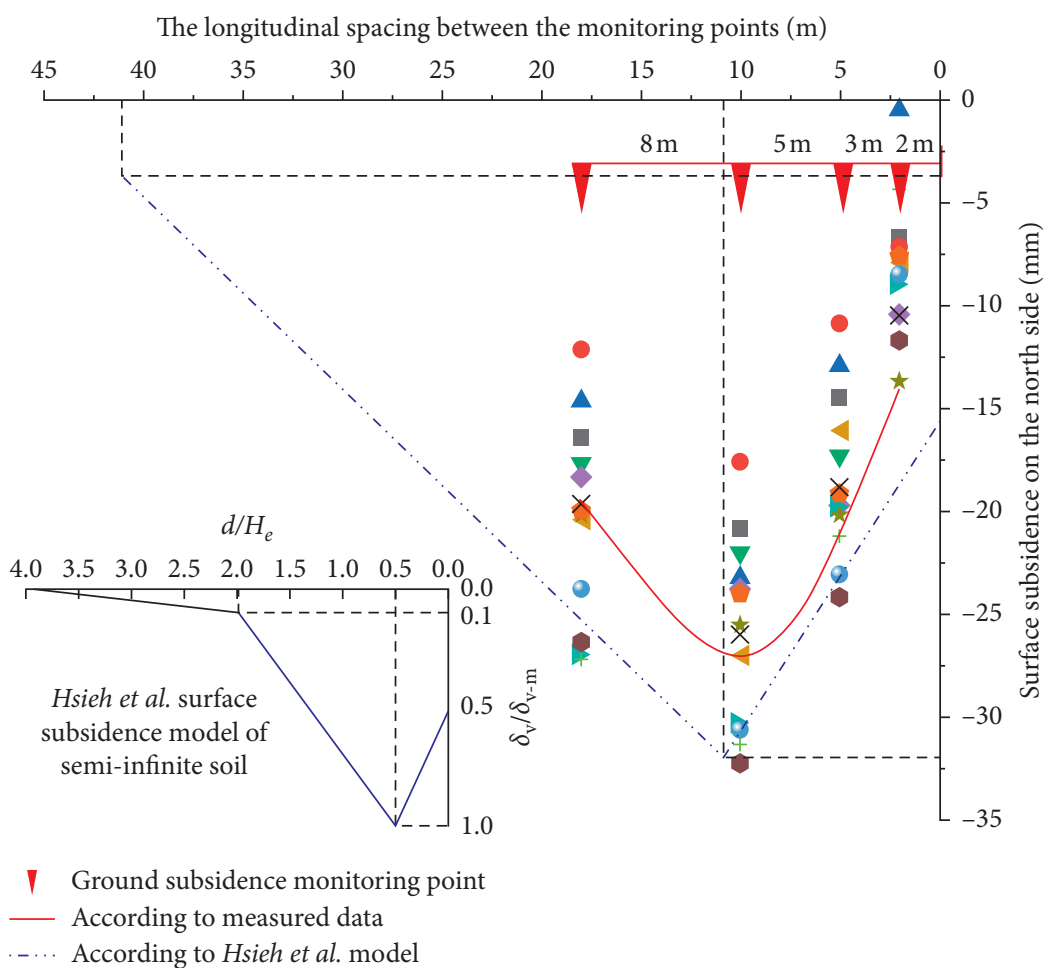

(a)

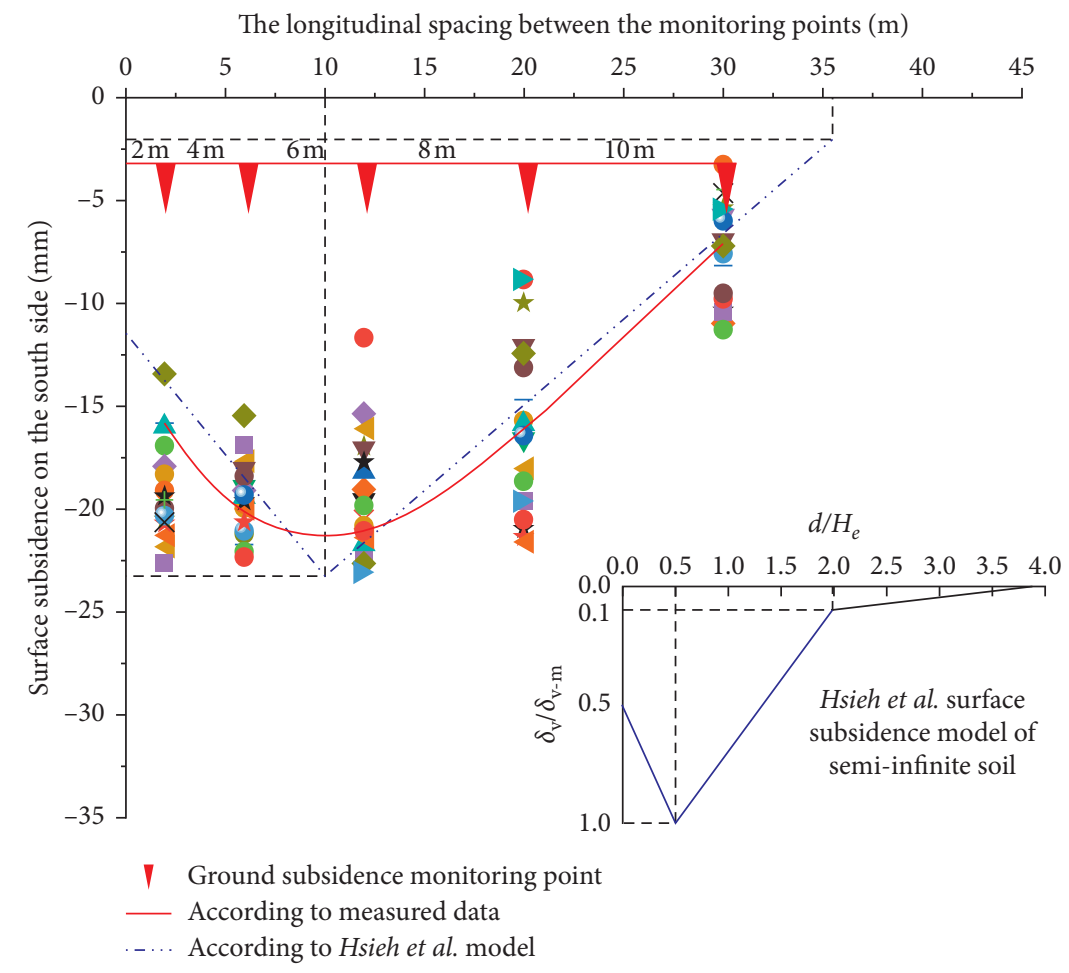

(b)

Figure 7: Prediction curve of ground subsidence and subsidence influence range in semi-infinite soil area: (a) north side of K0+600 K1+074 section of Gongchang Road Project; (b) south side of Sun Yat-Sen University Station.

method, which can be divided into two circular sliding modes according to the different center positions of circular: one takes the position at the bottom of pile wall as the center, and the other takes the lowest retaining point of pile wall as the center. In Asia, many regions such as Japan, Taiwan (China), and Shanghai (China) usually adopt the second 
TABLE 5: Characteristic values of ground subsidence in semi-infinite soil area.

Monitoring area

North side of $K 0+600-K 1+074$ section of Gongchang Road Project

South side of Sun Yat-Sen University Station
Characteristic values of ground subsidence in semiinfinite soil area $(\mathrm{mm})$

$\begin{array}{ccc}\delta_{v-\max } & \delta_{v-\min } & \delta_{v-\text { avg }} \\ -32.1 & -17.5 & -25.62 \\ -23.1 & -11.7 & -19.62\end{array}$

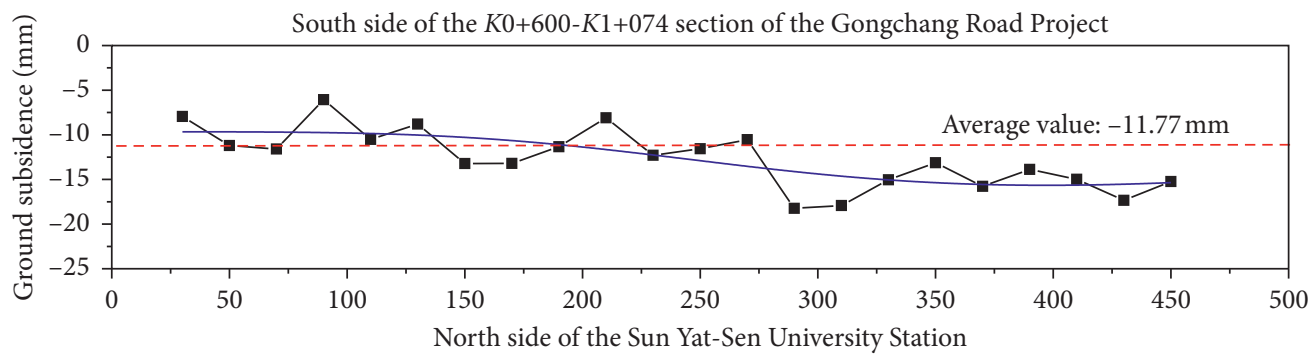

- - longitudinal ground subsidence curve of the south side of the Gongchang road project ( $\mathrm{mm}$ )

- longitudinal subsidence trend

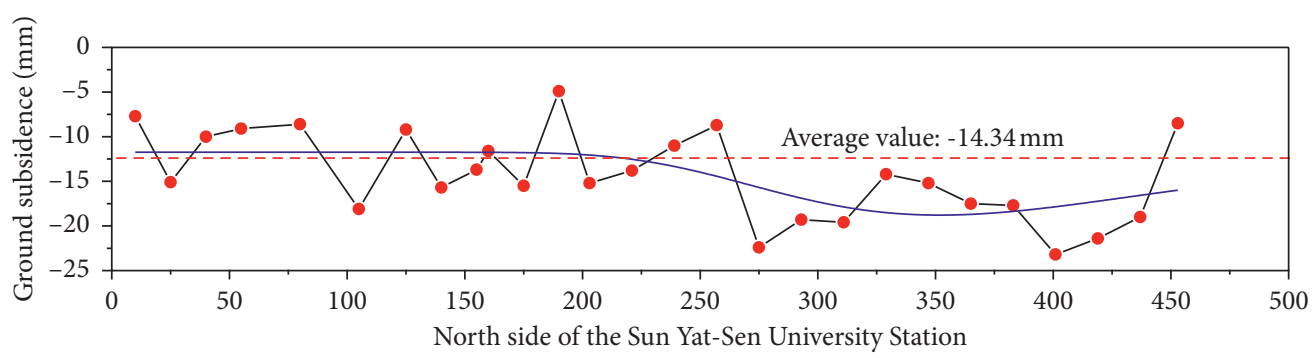

- - longitudinal ground subsidence curve of the north side of the Sun Yat-Sen University Station

— longitudinal subsidence trend

FIGURE 8: Longitudinal curve of ground subsidence and subsidence trend in finite soil area.

TABle 6: Characteristic values of ground subsidence in finite soil area.

\begin{tabular}{|c|c|c|c|}
\hline \multirow[t]{2}{*}{ Monitoring area } & \multicolumn{3}{|c|}{$\begin{array}{l}\text { Characteristic values of ground subsidence in finite } \\
\text { soil area }(\mathrm{mm})\end{array}$} \\
\hline & $\delta_{v-\max }$ & $\delta_{v-\min }$ & $\delta_{v-\mathrm{avg}}$ \\
\hline South side of $K 0+600 \sim K 1+074$ section of Gongchang Road Project & -18.24 & -6.06 & -11.77 \\
\hline North side of Sun Yat-Sen University Station & -23.20 & -4.90 & -14.29 \\
\hline
\end{tabular}

mode [26]. The computational mechanical model is shown in Figure 9.

There are two main types of the sliding moment: (1) the sliding moment $M_{q}^{S}$ produced by the overload $q$ in $a b$ section of the ground surface and (2) the sliding moment produced by the self-weight of the soil mass which includes $M_{o a b c}^{S}$ in oabc area, $M_{o a d i}^{S}$ in ocdi area, and $M_{\text {ide }}^{S}$ in ide area.

There are three types of antisliding moment: (1) allowable moment $M_{\mathrm{s}}$ of the retaining structure, (2) antisliding moment $M_{i e f}^{R}$ produced by the self-weight of soil in ief area, and (3) antisliding moment $M_{c e}^{R}$ and $M_{e f}^{R}$ produced by the shear strength on sliding surface $c e$ and $e f$.

It can be seen from the figure that the sliding moment $M_{i \text { de }}^{S}$ generated by the self-weight of the soil can be offset by the antisliding dynamic moment $M_{i e f}^{S}$, and the antisliding moment of the vertical sliding surface above the lowest support and the ultimate flexural strength of retaining structures are not considered [23] so that the situation can be relatively safe.

However, for ultra-adjacent deep foundation excavation, the stability calculation method for the interlayer between the foundation pits on both sides is different from the traditional one. Combined with the actual situation, this paper takes the most unfavorable working condition where foundation pits on both sides are excavated to the bottom as an example and divides the mechanical model for the against basal heave stability calculation of super-adjacent area into the following two cases based on the relationship between the horizontal spacing $L$ between adjacent foundation pits and the distance $D^{\prime}$ between the lowest support and the bottom of the retaining structure, as shown in Figure 10. 


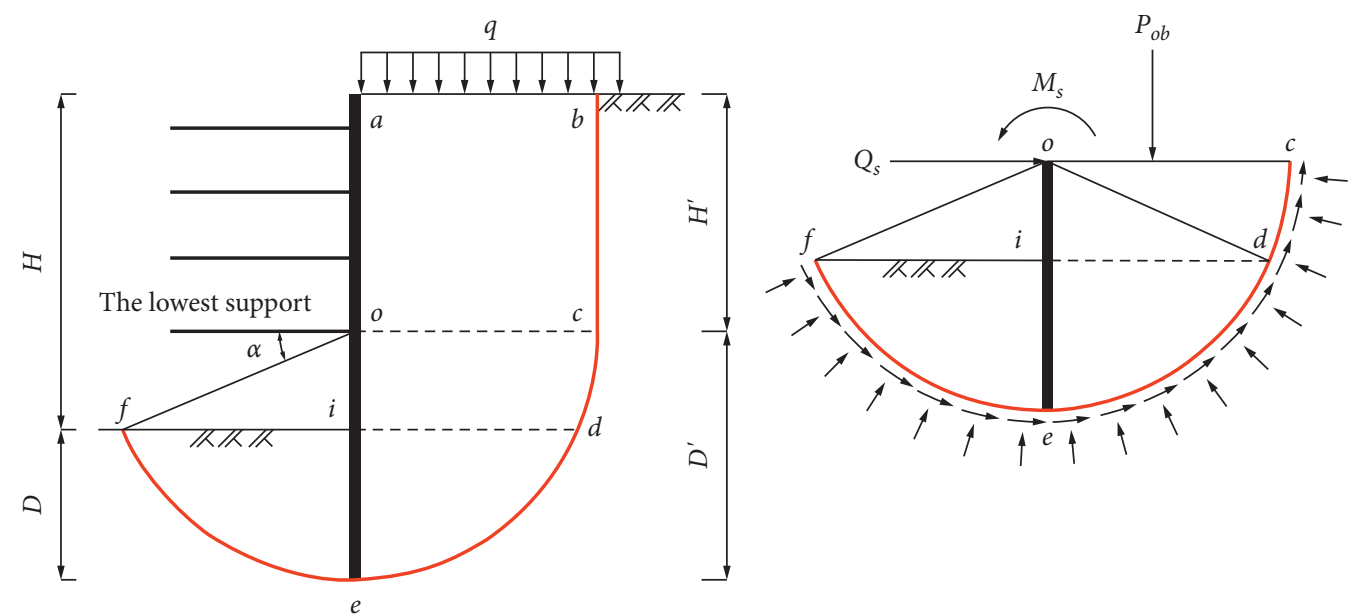

(a)

(b)

FIGURE 9: Schematic diagram of checking against basal heave stability of pit bottom based on circular arc sliding mode (homogeneous foundation) [22]: (a) failure surface; (b) isolation body.

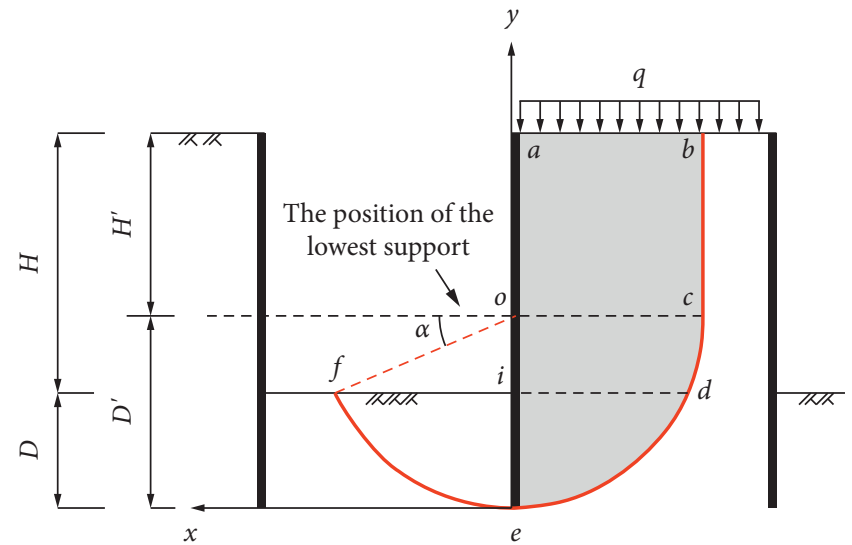

(a)

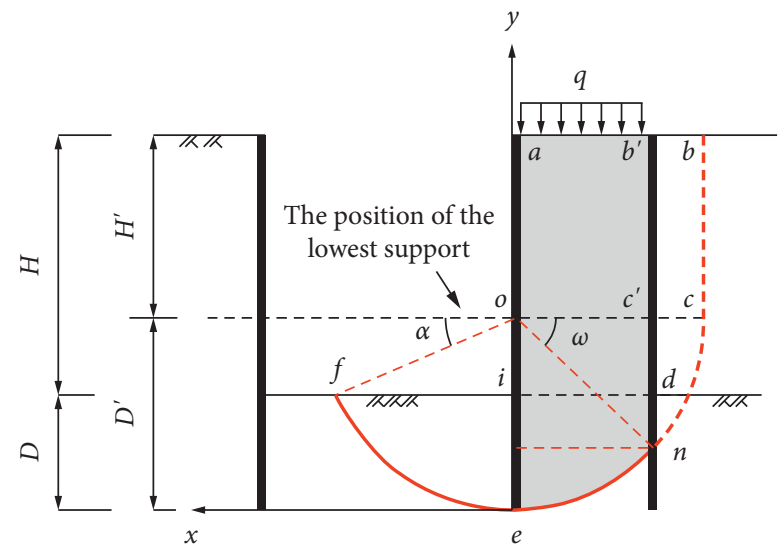

(b)

FIGURE 10: Schematic diagram of the assumed sliding surface of foundation bottom with different adjacent pit spacing: (a) $L \geq D^{\prime}$; (b) $L<D^{\prime}$.

4.1. Basic Assumptions and Simplification. Due to the complexity of working conditions and corresponding stress conditions of super-adjacent deep foundation pit in practical construction, further assumptions and simplification should be made in the study of its against basal heave stability. Taking the left foundation pit as the main research object, the basic assumptions are as follows:

(1) The stratum of foundation pits on both sides is homogeneous stratum; that is to say, the weighted average strength index of layered soil is equivalent to the homogeneous soil layer

(2) During the excavation of the right foundation pit, the unloading Earth pressure is balanced with the external force provided by the support of each layer
(3) The antisliding moment of the vertical sliding surface above the lowest support and the ultimate flexural strength of rock-like material retaining structure are not considered [28]

\subsection{Stability Analysis}

4.2.1. $L \geq D^{\prime}$. When $L \geq D^{\prime}$ as shown in Figure $10(\mathrm{a})$, the potential sliding mode of the foundation pit is consistent with the traditional mechanical mode. When $L=D^{\prime}$, the force on the vertical sliding surface above the lowest support increases from the antisliding force in the soil to the friction force between the retaining structures of the right foundation pit, so that the situation can be relatively safe when 
the traditional mechanical model is applied. Then, the antisliding moment $M_{1}^{R}$ and sliding moment $M_{1}^{S}$ in the first case are calculated as follows.

(1) Antisliding moment $M_{1}^{R}$ : (i) Antisliding moment on sliding surface ce: Shear strength $\tau_{\mathrm{ce}}$ [29] on sliding surface $c e$ is

$$
\tau_{c e}=\left[\left(q_{1}+\bar{\gamma} D^{\prime} \sin \theta\right) \sin ^{2} \theta+K_{a}\left(q_{1}+\bar{\gamma} D^{\prime} \sin \theta\right) \cos ^{2} \theta\right] \tan \bar{\varphi}+\bar{c},
$$

where $q_{1}=\bar{\gamma} H^{\prime}+q, \bar{\gamma}$ is the weighted average value of soil layer weight, $D^{\prime}$ is the depth of the retaining structure part below the lowest support, $H^{\prime}$ is the height of the retaining structure part above the lowest support, $K_{\mathrm{a}}$ is the active earth pressure coefficient of the corresponding soil layer, and $\theta$ is the angle in the lowest support and the line between the $o$ point and any point on the sliding surface $c e . \bar{c}$ and $\bar{\varphi}$ are the weighted average values of soil cohesion and internal friction angle, respectively.

Then, the antisliding moment of sliding surface ce is

$$
\begin{aligned}
M_{c e}^{R}= & \int_{0}^{\frac{\pi}{2}} \tau_{c e} D^{\prime 2} \mathrm{~d} \theta \\
= & \frac{\pi}{4}\left(1+K_{a}\right) D^{\prime 2} q_{0} \tan \varphi \\
& +\left(\frac{2}{3}+\frac{K_{a}}{3}\right) \gamma D^{3} \tan \varphi+\frac{\pi}{2} c D^{\prime} .
\end{aligned}
$$

(ii) Antisliding moment on sliding surface ef Shear strength on sliding surface ef is

$$
\tau_{e f}=\bar{\gamma}\left[D^{\prime} \sin \theta-\left(H-H^{\prime}\right)\right] \sin ^{2} \theta \tan \bar{\varphi}+K_{p} \bar{\gamma}\left[D^{\prime} \sin \theta-\left(H-H^{\prime}\right)\right] \cos ^{2} \theta \tan \bar{\varphi}+\bar{c}
$$

where $K_{\mathrm{p}}$ is the passive Earth pressure coefficient of the soil layer, $K_{p}=\tan \left(45^{\circ}+(\varphi / 2)\right)$, and $H$ is the excavation depth of the foundation pit. Thus, the antisliding moment on sliding surface ef is

$$
\begin{aligned}
& M_{e f}^{R}=\int_{\alpha}^{\pi / 2} \tau_{e f} D^{\prime 2} \mathrm{~d} \theta \\
& =\bar{\gamma} D^{3} \tan \bar{\varphi}\left(\cos \alpha-\frac{\cos ^{3} \alpha}{3}\right)-\bar{\gamma} D^{3} \tan \bar{\varphi} \sin \alpha \cdot\left[\frac{1}{2}\left(\frac{\pi}{2}-\alpha\right)+\frac{1}{4} \sin (2 \alpha)\right] \\
& +K_{p} \bar{\gamma} D^{3} \tan \bar{\varphi} \cdot \frac{\cos ^{3} \alpha}{3}-K_{p} \bar{\gamma} D^{\prime 3} \tan \bar{\varphi} \cdot \sin \alpha\left[\frac{1}{2}\left(\frac{\pi}{2}-\alpha\right)-\frac{1}{4} \sin (2 \alpha)\right]+\bar{c} D^{\prime}\left(\frac{\pi}{2}-\alpha\right), \\
& M_{1}^{S}=M_{o a b c}^{S}+M_{o c d i}^{S} \\
& =\frac{1}{2}\left(q+\bar{\gamma} H^{\prime}\right) D^{\prime 2}+\frac{1}{3} \bar{\gamma} D^{3} \sin \alpha+\frac{1}{6} \bar{\gamma} D^{\prime}\left(H-H^{\prime}\right) \cos ^{2} \alpha .
\end{aligned}
$$

$$
M_{1}^{R}=M_{c e}^{R}+M_{e f}^{R} .
$$

(2) Sliding moment $M_{1}^{S}$ :

At this time, the sliding moment is produced by the self-weight of soil in $o a b c$ area and ocdi area. Then, the total sliding moment $M_{1}^{S}$ is
4.2.2. $L<D^{\prime}$. When $L<D^{\prime}$, as shown in Figure $10(\mathrm{~b})$, the self-weight of soil in idne area is lighter than that in ief area. Thus, $\Delta M^{\mathrm{R}}$ should be added in the calculation of antisliding moment. 


$$
\Delta M^{R}=M_{i e f}^{R}-M_{i d n e}^{S}
$$

(i) Antisliding moment on sliding surface $n e$ : Shear strength $\tau_{\text {ne }}$ on sliding surface $n e$ is

(1) Antisliding moment $M_{2}^{R}$ :

$$
\tau_{n e}=\left\{\left[q_{2}+\bar{\gamma} D^{\prime}(1-\sin \omega)\right] \sin ^{2} \theta+K_{p} q_{2}+\bar{\gamma} D^{\prime}[(1-\sin \omega)] \cos ^{2} \theta\right\} \tan \bar{\varphi}+\bar{c},
$$

where $q_{2}=\bar{\gamma}\left(H^{\prime}+D^{\prime} \sin \omega\right)+q$ and $\omega=\arccos$ $\left(L / D^{\prime}\right)>\alpha$. Then, the antisliding moment on sliding surface $n e$ is

$$
\begin{aligned}
M_{n e}^{R}= & \int_{\omega}^{\pi / 2} \tau_{n e} D^{\prime 2} \mathrm{~d} \theta \\
= & \left\{\frac{\tan \bar{\varphi}}{4} D^{\prime 2}\left[q_{2}+\bar{\gamma} D^{\prime}(1-\sin \omega)\right] \cdot(\pi-2 \omega+\sin 2 \omega)\right\}+\left\{\frac{\tan \bar{\varphi}}{4} D^{\prime 2} K_{p}\left[q_{2}+\bar{\gamma} D^{\prime}(1-\sin \omega)\right] \cdot(\pi+2 \omega-\sin 2 \omega)\right\} \\
& +\bar{c} D^{\prime 2}\left(\frac{\pi}{2}-\omega\right) .
\end{aligned}
$$

(ii) Antisliding moment on sliding surface ef: At this time, the antisliding moment on sliding surface ef is the same as $M^{\mathrm{R}}$ ef in the first case. Then, the total antisliding moment is

$$
M_{2}^{R}=M_{n e}^{R}+M_{e f}^{R}+\Delta M^{R} .
$$

(4) Sliding moment $M_{2}^{S}$ :

At this time, the sliding soil area is the rectangular area $a b^{\prime} d i$ in Figure 10(b); then the sliding moment is

$$
M_{2}^{S}=\frac{1}{2}(\bar{\gamma} H+q)\left(D^{\prime} \cos \omega\right)^{2}
$$

Through the above division of the mechanical models for the against basal heave stability of rock-like material retaining structure with different adjacent degrees, the results can provide references for the stability calculation of similar projects. In practical application, the basic parameters of the retaining system of the foundation pits on both sides may be different, so the retaining system design should be carried out after calculating the parameters according to the above models, on the premise of satisfying the stability requirements of the foundation pits on both sides.

\section{Application and Verification of the Project}

Based on the above study on the calculation of anti-uplift stability of rock-like material envelope in super-adjacent engineering, this paper verifies the applicability of the calculation method through calculating the stability of the typical excavation section of Shenzhen Gongchang Road undercrossing tunnel project and applying relevant prediction theories.
5.1. Project Practice Verification. The typical section of Shenzhen Gongchang Road undercrossing tunnel adjacent to Sun Yat-Sen University Station and Science and Technology Town Station is selected for stability calculation, as shown in Figures 11(a) and 11(b). In Figure 11(a), the spacing of foundation pits on both sides is $L_{1}=3 \mathrm{~m}$, $D_{1}{ }^{\prime}=15 \mathrm{~m}$; in Figure 11(b), the spacing of foundation pits on both sides is $L_{2}=6 \mathrm{~m}$ and $D_{2}{ }^{\prime}=14.3 \mathrm{~m}$. Both of them belong to the second case of stability calculation; i.e., $L<D$ '.

According to the physical and mechanical parameters of the corresponding soil layer in Table 1, the weighted average values of the stability can be calculated, respectively, as homogeneous soil layer (weighted according to the thickness of each soil layer). According to the calculation, for the section in Figure 11(a), the safety and stability coefficient $K_{S}$ of the deep foundation pits of Gongchang Road undercrossing tunnel is 1.87, and for the section in Figure 11(b), $K_{s}=2.03$, which is basically consistent with the design scheme and meets the standards of the stability verification by circular sliding method for foundation pit with internal support required by the Technical Specification for Retaining and Protection of Building Foundation Excavation (JGJ1202012) and has enough safety reserve.

\subsection{Verification of Relevant Theories}

5.2.1. Verification Based on the Foundation Stability Prediction Theory of Wang et al. [30]: "The Relationship between the Stiffness of the Retaining System and the Maximum Relative Lateral Displacement of the Retaining Structure". The prediction method gives the diagram of the relationship between the stiffness of the retaining system, the maximum relative lateral displacement of the retaining structure, and the stability coefficient, as shown in Figure 12, in which $E I / h^{4} \gamma_{\mathrm{w}}$ is the stiffness of the retaining system, $E$ is the elastic modulus of 


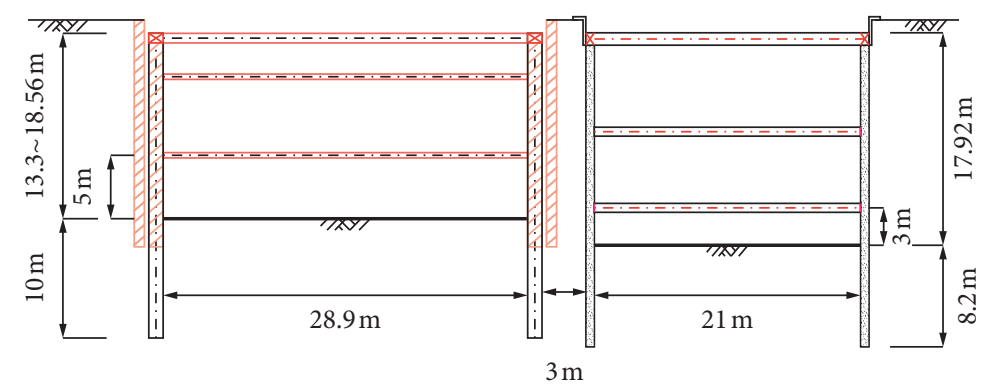

(a)

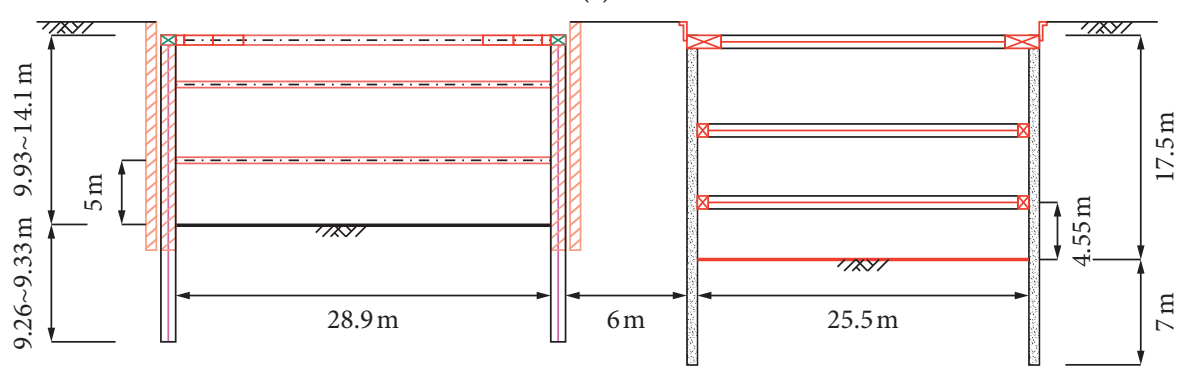

(b)

FIgURE 11: Typical section diagram of foundation pits in the adjacent area between Gongchang Road undercrossing tunnel and Metro Line 6 extension stations: (a) $K 0+744 \sim K 0+857$; (b) $K 2+716 \sim K 2+900$.

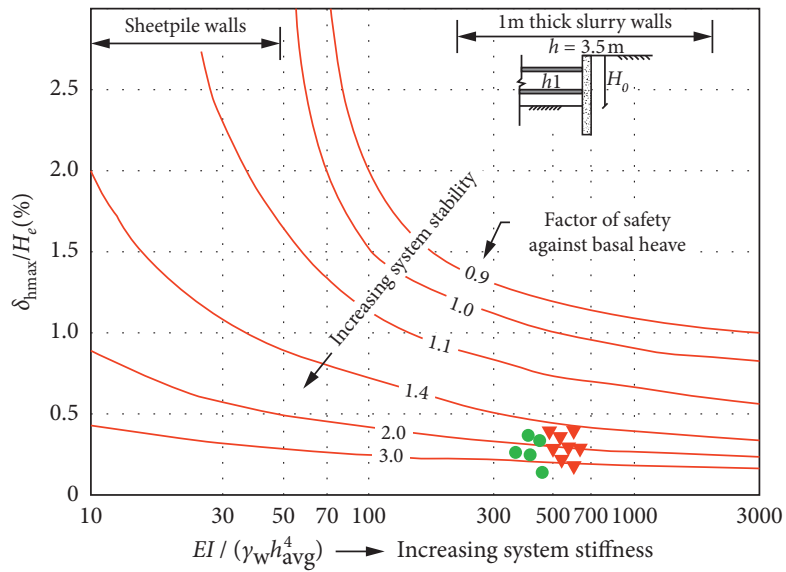

FiguRE 12: Curves of the relationship between the maximum lateral displacement of retaining structure and stiffness of the retaining system.

reinforced concrete support, $I$ is the inertia moment of the internal support section, $\gamma_{\mathrm{w}}$ is the standard weight of water, and $h$ is the vertical spacing of internal support. Taking the foundation pit of Gongchang Road adjacent to Sun Yat-Sen University Station as the verification object, the measured maximum lateral displacement of retaining structures in several sections of this area is selected, as shown in Figure 12. Combined with the stiffness of the retaining system of the project, the corresponding positions in the figure are marked. The red triangle marks the data points of the retaining structure on the north side of the foundation pit, while the green circle marks the data points of the retaining structure on the south side. The results show that they are highly consistent with the stability calculation results in Section 4.2.
5.2.2. Verification Based on the Prediction Theory of Mana and Clough [31]: "Factor of Safety of the Foundation StabilityMaximum Relative Lateral Displacement of Retaining Structure" of the Position of the Lowest Support and the Embedded Depth of Retaining Structure. Figure 13 shows the curve of the relationship between the maximum relative lateral displacement of the retaining structure and the factor of safety of the against basal heave stability. The curve is fitted by Mana by combining the measured data at the bottom of the retaining structure in different areas under different constraint conditions. It can also reflect the influence of the position of the lowest support, the embedded depth of the retaining structure, and other factors on the stability of the bottom. Combining the measured 


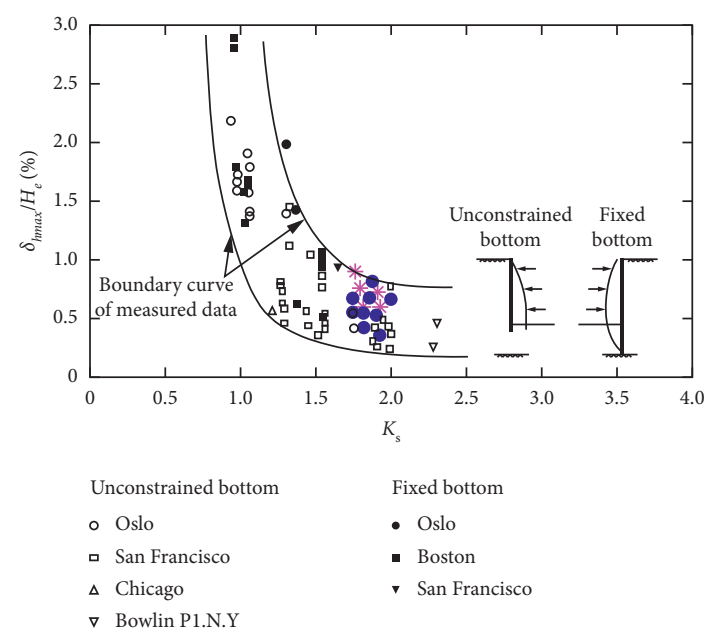

FIGURE 13: Curves of the relationship between the maximum relative displacement of retaining structure and factor of safety of the against basal heave stability.

deformation data and the section size of the north and south sides of the retaining structure of the project, the calculation results based on the stability theory in Section 4.2 are drawn into the corresponding positions in the figure, in which the blue polygon marks the data points of the retaining structure on the north side of the foundation pit, and the pink star marks the data points of the retaining structure on the south side. This also verifies the applicability of the analysis method for the against basal heave stability of super-adjacent deep foundation pits.

\section{Conclusion}

(1) In the process of super-adjacent collaborative construction of road tunnels by open excavation and subway stations, due to the difference of rock-like material retaining systems on both sides, the upper part of the retaining structure and the finite soil in the adjacent area have inclined to one side at the same time, and the ground subsidence in the finite soil area also increased with the excavation depth of the foundation pit. Since the deformation of the adjacent area directly affects the stability of foundation pits on both sides, the deformation control should be fully considered in the design of rock-like material retaining system

(2) Taking the calculation method of foundation stability of circular sliding theory based on limit equilibrium method, the mechanical models and formulas for rocklike material retaining structure stability calculation under the conditions of $L \geq D^{\prime}$ and $L<D^{\prime}$ are given, respectively, according to the stability requirements for open excavations with different adjacent degrees. Through the application in practical construction and the verification of related theories, it is confirmed that the research results of this paper have strong applicability to similar projects

(3) In the process of theoretical research, this paper simplifies and assumes the research object. In the follow-up studies, the applicability of the theory can be optimized, and the mechanical models for rock-like material retaining structure stability analysis of different retaining system types and super-adjacent deep foundation pits with comprehensive retaining stiffness can also be further studied

\section{Data Availability}

The measured data used to support the findings of this study are included within the article.

\section{Conflicts of Interest}

The authors declare that they have no conflicts of interest.

\section{Acknowledgments}

This research was supported by the Science and Technology Project of China Communications First Bureau Group Co. Ltd, grant no. 4GS (J)-GUD-GCL-01-JS-016, and the National Natural Science Foundation of China, grant no. 51278233.

\section{References}

[1] Editorial Department of China Journal of Highway and Transport, "Review on China's tunnel engineering reseach: 2015," China Journal of Highway and Transport, vol. 28, no. 6, pp. 1-65, 2015, in Chinese.

[2] R. Chen, F. Meng, Z. Li, Y. Ye, and J. Ye, "Investigation of response of metro tunnels due to adjacent large excavation and protective measures in soft soils," Tunnelling and Underground Space Technology, vol. 58, pp. 224-235, 2016.

[3] H. Zheng, P. Li, and G. W. Ma, "Stability analysis of the middle soil pillar for asymmetric parallel tunnels by using model testing and numerical simulations," Tunnelling and Underground Space Technology, vol. 108, 2021.

[4] B. Liu, D. Zhang, C. Yang, and Q. Zhang, "Long-term performance of metro tunnels induced by adjacent large deep excavation and protective measures in Nanjing silty clay," Tunnelling and Underground Space Technology, vol. 95, no. 1, pp. 1-15, 2020.

[5] H. Huang, X. Huang, and D. Zhang, "Centrifuge modelling of deep excavation over existing tunnels," Proceedings of the ICEGeotechnical Engineering, vol. 167, no. 1, pp. 3-18, 2015.

[6] C. W. W. Ng, J. Shi, and Y. Hong, "Three-dimensional centrifuge modelling of basement excavation effects on an existing tunnel in dry sand," Canadian Geotechnical Journal, vol. 50, no. 8, pp. 874-888, 2013.

[7] H. Sun, Y. Chen, J. Zhang, and T. Kuang, "Analytical investigation of tunnel deformation caused by circular foundation pit excavation," Computers and Geotechnics, vol. 106, no. 2, pp. 193-198, 2019.

[8] Z. Zhang, M. Zhang, and Q. Zhao, "A simplified analysis for deformation behavior of buried pipelines considering disturbance effects of underground excavation in soft clays," Arabian Journal of Geosciences, vol. 8, no. 10, pp. 7771-7785, 2015.

[9] Z. Zhang, M. Huang, and W. Wang, "Evaluation of deformation response for adjacent tunnels due to soil unloading in 
excavation engineering," Tunnelling and Underground Space Technology, vol. 38, pp. 244-253, 2013.

[10] X. Zhang, X. Ou, J. Yang, and J. Fu, "Deformation response of an existing tunnel to upper excavation of foundation pit and associated dewatering," International Journal of Geomechanics, vol. 17, no. 4, pp. 1-14, 2016.

[11] X. Hao, W. Du, Y. Zhao et al., "Dynamic tensile behaviour and crack propagation of coal under coupled static-dynamic loading," International Journal of Mining Science and Technology, vol. 30, no. 5, pp. 659-668, 2020.

[12] X. Hao, Y. Wei, K. Yang et al., "Anisotropy of crack initiation strength and damage strength of coal reservoirs," Petroleum Exploration and Development, vol. 48, no. 1, pp. 243-255, 2021.

[13] J. Lou, F. Gao, J. Yang, and Y. Ren, "Characteristics of evolution of mining-induced stress field in the longwall panel: insights from physical modeling," International Journal of Coal Science and Technology, vol. 2021, Article ID 2785933, 2021.

[14] S.-H. Li, M.-J. Zhang, and P.-F. Li, "Analytical solutions to ground settlement induced by ground loss and construction loadings during curved shield tunneling," Journal of Zhejiang University-Science A, vol. 22, no. 4, pp. 296-313, 2021, in Chinese.

[15] M. J. Schuster, C. H. Juang, E. C. L. Hsiao, M. J. S. Roth, and G. T. C. Kung, "Reliability analysis and updating of excavation-induced ground settlement for building serviceability assessment," Journal of Geotechnical \& Geoenvironmental Engineering, vol. 134, pp. 1448-1458, 2008.

[16] G. T. Kung, C. H. Juang, E. C. Hsiao, and Y. M. Hashash, "Simplified model for wall deflection and ground-surface settlement caused by braced excavation in clays," Journal of Geotechnical and Geoenvironmental Engineering, vol. 133, no. 6, pp. 731-747, 2007.

[17] S. H. Li, P. F. Li, and M. J. Zhang, "Analysis of additional stress for a curved shield tunnel," Tunnelling and Underground Space Technology, vol. 107, Article ID 103675, 2021.

[18] I. E. Avramidis and K. Morfidis, "Bending of beams on threeparameter elastic foundation," International Journal of Solids and Structures, vol. 43, no. 2, pp. 357-375, 2006.

[19] S. J. Boone, "Ground-movement-related building damage," Journal of Geotechnical Engineering, vol. 122, no. 11, pp. 886-896, 1996.

[20] R. J. Finno and L. S. Bryson, "Response of building adjacent to stiff excavation support system in soft clay," Journal of Performance of Constructed Facilities, vol. 16, no. 1, pp. 10-20, 2002.

[21] K. H. Goh and R. J. Mair, "Building damage assessment for deep excavations in Singapore and the influence of building stiffness," Geotechnical Engineering Journal of the SEAGS \& AGSSEA, vol. 42, no. 3, pp. 1-12, 2011.

[22] J. S. Sharma, A. M. Hefny, J. Zhao, and C. W. Chan, "Effect of large excavation on deformation of adjacent MRT tunnels," Tunnelling and Underground Space Technology, vol. 16, no. 2, pp. 93-98, 2001.

[23] H. Sun, L. Wang, S. Chen, H. Deng, and J. Zhang, "A precise prediction of tunnel deformation caused by circular foundation pit excavation," Applied Sciences, vol. 9, no. 11, Article ID 2275, 2019.

[24] M. Schuster, T. Kung, C. H. Juang, and Y. M. A. Hashash, "Simplified model for evaluating damage potential of buildings adjacent to a braced excavation," Journal of Geotechnical \& Geoenvironmental Engineering, vol. 135, no. 12, pp. 18231835, 2015.
[25] Z. Wang, F. Zhou, P. Zhou, Y. Jiang, S. Deng, and R. Ren, "Research on deformation theory of existing station based on single side excavation and unloading of large foundation pit with strong close connection," Chinese Journal of Rock Mechanics and Engineering, vol. 39, pp. 2131-2147, 2020, in Chinese.

[26] G. W. Clough and T. D. O'Rourke, "Construction induced movements of in situ wall," Geotechnical Special Publication, vol. 25, pp. 439-470, 1990.

[27] P.-G. Hsieh and C.-Y. Ou, "Shape of ground surface settlement profiles caused by excavation," Canadian Geotechnical Journal, vol. 35, no. 6, pp. 1004-1017, 1998.

[28] P.-G. Hsieh, C.-Y. Ou, and H.-T. Liu, "Basal heave analysis of excavations with consideration of anisotropic undrained strength of clay," Canadian Geotechnical Journal, vol. 45, no. 6 , pp. 788-799, 2008.

[29] H. Wang, "Influence of excavation width on enclosurestructure stability of foundation pits," Rock and Soil Mechanics, vol. 37, no. s2, pp. 433-441, 2016, in Chinese.

[30] H. Wang, J. Chen, and J. Liu, "Practical calculation analysis and application of factor of safety of heave-resistant stability of foundation pit," Chinese Journal of Rock Mechanics and Engineering, vol. 26, no. s1, pp. 3223-3230, 2007, in Chinese.

[31] A. I. Mana and G. W. Clough, "Prediction of movement for braced cuts in clay," Journal of the Geotechnical Engineering Division, vol. 107, no. GT6, pp. 759-777, 1981. 